European Journal of Sustainable Development

Research, 2018, 2(1), 06

ISSN: $2542-4742$

\title{
Descriptive Analysis of Viewpoint of Students and Faculty towards Information and Communication Technology in Relation to Gender: A Case Study of Indian Universities
}

\author{
Chaman Verma ${ }^{1 *}$, Veronika Stoffová ${ }^{2}$, Illés Zoltán ${ }^{1}$
}

\author{
${ }_{1}$ Department of Media and Educational Informatics, Faculty of Informatics, Eötvös Loránd University, Budapest, \\ HUNGARY \\ ${ }^{2}$ Department of Mathematics and Computer Science, Faculty of Education, Trnava University in Trnava, Trnava, \\ SLOVAKIA
}

*Corresponding Author: chaman.verma@gmail.com \& chaman@inf.elte.hu

Citation: Verma, C., Stoffová, V. and Zoltán, I. (2018). Descriptive Analysis of Viewpoint of Students and Faculty towards Information and Communication Technology in Relation to Gender: A Case Study of Indian Universities. European Journal of Sustainable Development Research, 2(1), 06. https://doi.org/10.20897/ejosdr/74240

Published: January 30, 2018

\begin{abstract}
This paper explores the current scenario of Information and communication technology (ICT) awareness in Government and Private Universities located in two northern states in India. It emphasizes on the faculty and student's viewpoints towards ICT awareness in relation to their gender. The author is analyzed the viewpoint of students and faculty who are providing and receiving higher education in government and private Institutions located in northern India. Gender wise analysis is performed using descriptive percentage analysis. Further, the range of response analysis is performed for explore viewpoints of students towards information and communication technology factors. More than nine hundred participants from six Universities have participated in this research. The outcome shows the huge necessity to integrate the higher education with latest technology in northern Indian Universities. The normative survey was conducted in the year 2015 by researcher.
\end{abstract}

Keywords: range of responses, percentage analysis, viewpoints, mean, standard deviation

\section{INTRODUCTION}

In last few years, technological access of higher education and research in India has increased swiftly. Most of researchers, faculty and students are using information and communication technology in their study and research work. For successful integration of technology, viewpoint of students and faculty plays an important role. The author felt the need to investigate the viewpoint of students and faculty towards information and communication technology awareness in their field of study. Many investigators have conducted gender wise analysis in educational Universities. Ahamad (2015) found significant difference between male and female students towards ICT. Mahajan and Sharma (2012) concluded that University has equipped with ICT based infrastructure and services: Single Window Integrated Software based solution, Campus Network Redundancy Link (3000 users), IP Telephony, Cloud Facility, Virtual Classroom Facility, Wi-Fi Internet with security, Threat Behavior Analysis Tool and Viruses and Patch server etc. Nikkah and Mehra (2014) found difference among the means of attitude scores of university teachers with low, moderate and high computer competency scores was found to be significant at the level 0.01 confidence. Francisca (2012) and Indu et al. (2012) also found significant difference in the competence in the use of ICT by male and female students. In this paper, the author has studied on the following five aspects of information and communication technology awareness for the purpose of investigation. 


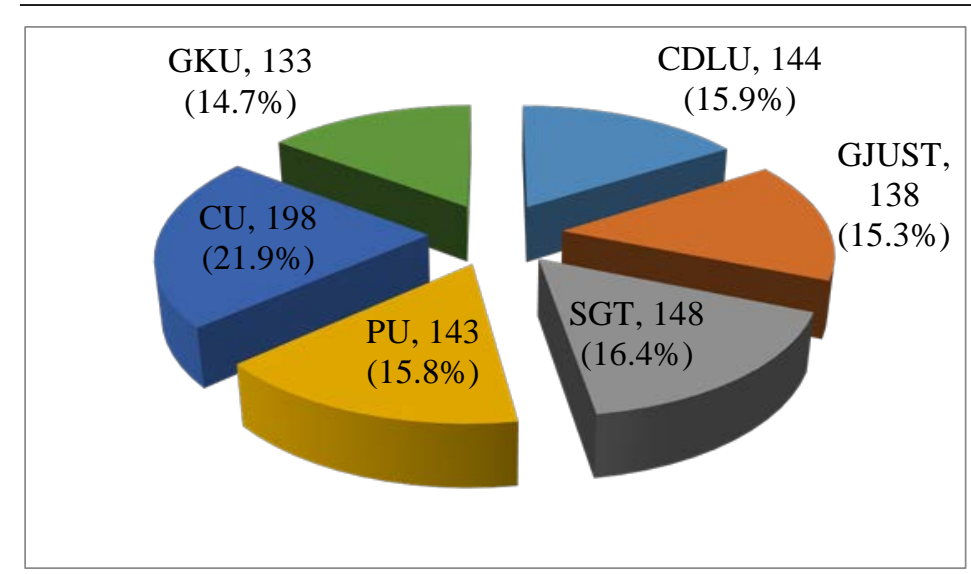

Figure 1. University's Samples, (Source: Author)

\section{Availability}

This factor defines availability or existence of ICT infrastructure, ICT tools/software, funds, E-libraries, Ejournals, ICT integration policy framework and Internet and bandwidth etc. Hence, author has included 10 variables under availability factor $\left(A_{v}\right)$.

\section{Usability}

The Usability $\left(\mathrm{U}_{\mathrm{s}}\right)$ describes accessibility of already available existing ICT tools and resources in teaching, learning and research work. It also explores usability of E-libraries, E-Journals and project development etc. Therefore, the author has considered 8 variables beneath it.

\section{Problem}

The problem factor $\left(\mathrm{P}_{\mathrm{r}}\right)$ explores real scenario of issues or barriers to access or implement ICT infrastructure and resources in the educational life of both students and faculty such as lack of willingness, lack of proper training, time consume to integration ICT in education etc. Thus, author has mentioned three variables for problem factor.

\section{Solution}

The solution $\left(\mathrm{S}_{1}\right)$ discusses about to resolve the problems faced by participants in their Institutions. It also gives some suggestions to authorities and participants, about the requirement of training, funds, increase bandwidth, Ejournals and policies etc. Finally, 5 variables represent this factor.

\section{Opportunity}

This factor introduces the benefits and prospects which ICT involves in various tasks such as education, placement, planning, management, admission, examination in institutions. It also describes the motivational perspective of ICT integration in higher education. The author has included 9 variables below opportunity $\left(\mathrm{O}_{\mathrm{p}}\right)$.

\section{POPULATION}

Total 904 Students and Faculty from various Universities located in Punjab and Haryana state of India, have participated in the present study. There are three Universities from each state. The name and affiliation status of Universities are given below:

1. Ch. Devi Lal University (CDLU)- Government, Sirsa

2. Guru Jambheshwar University of Science \& Tech. (GJUST)- Government, Hisar

3. Shree Guru Gobind Singh TriCentenary University (SGT)-Private, Gurgaon

4. Punjabi University (PU)- Government, Patiala

5. Chandigarh University (CU)- Private, Mohali

6. Gurukashi University (GKU)- Private, Bathinda

Figure 1 presents the distribution of samples from six Universities under study. There are 133 (14.75) participants from GKU, 144 (15.9\%) from CDLU, 138 (15.3\%) from GJUST, 148 (16.4\%) from SGT, $143(15.8 \%)$ from PU and 198 (21.9\%) participants are from CU. The maximum samples are collected from Chandigarh University due to huge strength of students and faculties. 


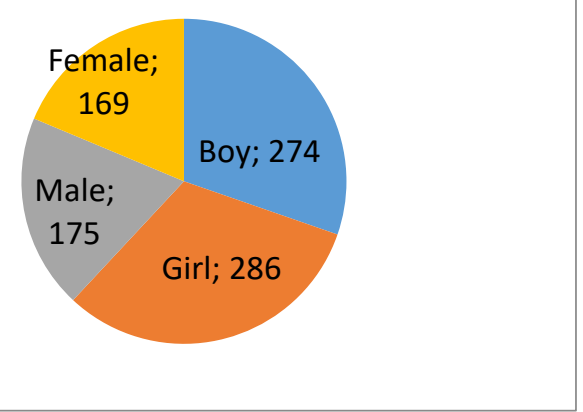

Figure 2. Gender Wise Students and Faculty Participants, (Source: Author)

\section{SAMPLING \& TOOL USED}

The stratified random sampling is used to collect data of faculty and students from universities. The samples of girls student are more than of boys student $(286>274)$. But the strength of male faculty is more than that of female. (175>169). This data is analyzed using Microsoft Excel 2007 with data analysis tool pack.

Figure 2 shows the total count for boy and girl is 274 and 286 respectively out of total 560 students. Another side from total 344 faculty, 175 male and 169 female have participated.

\section{PERCENTAGE ANALYSIS OF BOY'S VIEWPOINT}

This section explores the descriptive analysis of boy student's viewpoints towards ICT. The author applied percentage analysis using various functions such as count $($, percentage $($, $\max ($, $\min (\mathrm{in}$ Ms-Excel 2007. The five point likert scale is applied to gather data: Strongly Disagree (SD), Disagree (D), Undecided (D), Agree (A) and Strongly Agree (SA).

Data from Table 1 shows percentage analysis of viewpoints of boy students of two states collectively. For the statement "Adequate ICT infrastructure is available" under variable no.1, there are $50 \%$ boys are agree $(\mathrm{A}), 6 \%$ are strongly agree (SA), $12 \%$ are strongly disagree (SD), $21 \%$ are disagree $(\mathrm{D})$ and remaining $12 \%$ are undecided $(\mathrm{U})$. It shows that there is wide need to provide sufficient ICT infrastructure in higher educational Institutions in Haryana and Punjab. In case of statement "Institution campus is Wi-fi." under variable no.2, there are $48 \%$ boys are agree, $20 \%$ are strongly agree, $11 \%$ are strongly disagree, $13 \%$ are disagree and only $8 \%$ are undecided. It proves the speed of Wireless Internet facility in institutions. For the statement "Sufficient bandwidth is available for Internet" under variable no.3, there are $34 \%$ boys are agree, $16 \%$ are strongly agree, $14 \%$ are strongly disagree, $23 \%$ are disagree and only $13 \%$ are undecided. It proves that $50 \%$ boys committed that there is sufficient Internet bandwidth available in institution. For the statement "ICT tools/software are easy accessible" under variable no.4, there are $39 \%$ boys are agree, $9 \%$ are strongly agree, $11 \%$ are strongly disagree, $22 \%$ are disagree and only $20 \%$ are undecided. It reflects that the ICT tools are not easy accessible by stakeholders. In case of the statement "Institutions have clear policy framework to integrate ICT" under variable no. 5 , there are 33\% boys are agree, $12 \%$ are strongly agree, $11 \%$ are strongly disagree, $14 \%$ are disagree and only $30 \%$ are undecided. It proves that Institutions should adapt transparent policies to involve ICT in higher education and research.

For the statement "Sufficient funds are available to promote ICT based research and development" under variable no.6, there are $35 \%$ boys are agree, $10 \%$ are strongly agree, $12 \%$ are strongly disagree, $15 \%$ are disagree and only $28 \%$ are undecided. It shows that there is lack of sufficient funds in higher educational institutions to promote ICT based research and development. For the statement "Sufficient ICT tools/software and hardware are available in research laboratory" under variable no.7, there are 38\% boys are agree, $9 \%$ are strongly agree, $12 \%$ are strongly disagree, $22 \%$ are disagree and only $19 \%$ are undecided. It concludes that $47 \%$ boys agreed that there is need to provide sufficient ICT tools/software and hardware in research laboratories of Institutions. In case of the statement "Institutions have E-library" under variable no.8, there are 33\% boys are agree, $15 \%$ are strongly agree, $17 \%$ are strongly disagree, $18 \%$ are disagree and only $17 \%$ are undecided. It infers that there is wide need to establish E-librarires in higher educational institutions. For the statement "Adequate E-journals/ E-contents are available in Library" under variable no.9, there are $23 \%$ boys are agree, $11 \%$ are strongly agree, $19 \%$ are strongly disagree, $23 \%$ are disagree and only $22 \%$ are undecided. It shows that there is lack of E-journals and E-contents in target institution's libraries. For the statement "E-contents are easily accessible/subscribed in library" under variable no.10, there are 33\% boys are agree, $9 \%$ are strongly agree, $14 \%$ are strongly disagree, $23 \%$ are disagree 
Table 1. Percentage Analysis of Viewpoints of Boy student towards ICT

\begin{tabular}{|c|c|c|c|c|c|c|c|}
\hline \multirow{3}{*}{ Factors } & \multirow{3}{*}{$\begin{array}{l}\text { VAR. } \\
\text { No. }\end{array}$} & \multirow{3}{*}{ Dependant Variables } & \multicolumn{5}{|c|}{ Boys } \\
\hline & & & SD & D & UD & A & SA \\
\hline & & & \multicolumn{5}{|c|}{ Percentage (\%) } \\
\hline \multirow{10}{*}{$A_{v}$} & 1 & Adequate ICT infrastructure is available. & 12 & 21 & 12 & 50 & 6 \\
\hline & 2 & Institution campus is WI-fi. & 11 & 13 & 8 & 48 & 20 \\
\hline & 3 & Sufficient bandwidth is available for Internet. & 14 & 23 & 13 & 34 & 16 \\
\hline & 4 & ICT tools/software are easy accessible. & 11 & 22 & 20 & 39 & 9 \\
\hline & 5 & Institutions have clear policy framework to integrate ICT & 11 & 14 & 30 & 33 & 12 \\
\hline & 6 & $\begin{array}{l}\text { Sufficient funds are available to promote ICT based research and } \\
\text { development. }\end{array}$ & 12 & 15 & 28 & 35 & 10 \\
\hline & 7 & $\begin{array}{l}\text { Sufficient ICT tools/software and hardware are available in research } \\
\text { laboratory. }\end{array}$ & 12 & 22 & 19 & 38 & 9 \\
\hline & 8 & Institutions have E-library. & 17 & 18 & 17 & 33 & 15 \\
\hline & 9 & Adequate E-journals/ E-contents are available in Library. & 19 & 25 & 22 & 23 & 11 \\
\hline & 10 & E-contents are easily accessible/subscribed in library & 14 & 23 & 20 & 33 & 9 \\
\hline \multirow{8}{*}{$\mathrm{U}_{\mathrm{s}}$} & 11 & ICT used in Planning and Management. & 4 & 11 & 27 & 43 & 16 \\
\hline & 12 & ICT tools/software used in research and development are reliable. & 9 & 18 & 21 & 43 & 8 \\
\hline & 13 & Use of ICT encourages research and project development. & 4 & 11 & 16 & 51 & 19 \\
\hline & 14 & ICT is used to exchange the research information with other organizations. & 4 & 11 & 21 & 47 & 17 \\
\hline & 15 & ICT is used adequately in teaching, learning and research activities. & 5 & 16 & 14 & 47 & 18 \\
\hline & 16 & E-journals/ E-contents are effectively using in research and development. & 13 & 19 & 22 & 32 & 14 \\
\hline & 17 & ICT is used to access the E-contents from other libraries. & 6 & 13 & 21 & 43 & 17 \\
\hline & 18 & $\begin{array}{l}\text { ICT is used to learn the lecture/lesson from other institutions experts } \\
\text { through video conferencing. }\end{array}$ & 8 & 6 & 13 & 43 & 30 \\
\hline \multirow{3}{*}{$\mathrm{P}_{\mathrm{r}}$} & 19 & $\begin{array}{l}\text { Time consuming to integrate ICT into teaching, learning, research and } \\
\text { development. }\end{array}$ & 13 & 16 & 24 & 31 & 16 \\
\hline & 20 & Lack of readiness to adopt ICT technology in Teaching and Learning. & 3 & 15 & 18 & 39 & 26 \\
\hline & 21 & ICT tools/software not user friendly due to lack of training. & 7 & 16 & 22 & 35 & 20 \\
\hline \multirow{5}{*}{$\mathrm{S}_{1}$} & 22 & Need to upgrade the latest ICT infrastructure. & 4 & 8 & 12 & 46 & 31 \\
\hline & 23 & Internet bandwidth should be increased. & 1 & 4 & 12 & 41 & 42 \\
\hline & 24 & Need to increase E-journals/ E-contents as per requirement & 4 & 8 & 12 & 46 & 31 \\
\hline & 25 & Need to enhance ICT in Teaching and Learning. & 1 & 5 & 12 & 44 & 38 \\
\hline & 26 & Need for training/workshop to learn ICT tools/software and equipment. & 6 & 4 & 3 & 47 & 34 \\
\hline \multirow{9}{*}{$\mathrm{O}_{\mathrm{p}}$} & 27 & ICT increase the effective teaching and E-learning in classroom. & 9 & 11 & 16 & 39 & 24 \\
\hline & 28 & $\begin{array}{l}\text { Students and Teachers feel more professional, motivated and confident } \\
\text { while using ICT resources. }\end{array}$ & 2 & 9 & 15 & 43 & 30 \\
\hline & 29 & ICT provides more comprehensive material on particular topic. & 4 & 8 & 13 & 50 & 24 \\
\hline & 30 & ICT plays an important role in Admission and Examination. & 3 & 8 & 16 & 44 & 30 \\
\hline & 31 & Integrate of ICT increase Placement activities. & 4 & 9 & 13 & 46 & 29 \\
\hline & 32 & ICT reduce the cost for information exchange & 2 & 9 & 15 & 48 & 26 \\
\hline & 33 & ICT helps in designing to new projects in higher education. & 4 & 3 & 7 & 56 & 31 \\
\hline & 34 & Successful ICT integration will brighten the future of Higher education & 2 & 3 & 11 & 49 & 35 \\
\hline & 35 & Using the ICT available increases productivity in Higher Education. & 1 & 4 & 14 & 49 & 32 \\
\hline
\end{tabular}
(Source: Author)

and $20 \%$ are undecided. It proves that E-contents should be provide easily and approachable in Institutional libraries. In relation to the statement "ICT used in Planning and Management" related to variable no.11, there are $43 \%$ boys are agree, $16 \%$ are strongly agree, $4 \%$ are strongly disagree, $11 \%$ are disagree and $27 \%$ are undecided. It is visible from this analysis that $59 \%$ boys committed about the use of ICT in Planning and Management activities. In case of of the statement "ICT tools/software used in research and development are reliable." Relating to variable no. 12 , there are $43 \%$ boys are agree, $8 \%$ are strongly agree, $9 \%$ are strongly disagree, $18 \%$ are disagree and $21 \%$ are undecided. It shows $27 \%$ boys felt that ICT tools/software used in research and development are not reliable in use.

For the statement "Use of ICT encourages research and project development" under variable no.13, there are $51 \%$ boys are agree, $19 \%$ are strongly agree, $4 \%$ are strongly disagree, $11 \%$ are disagree and $16 \%$ are undecided. It proves that $70 \%$ boys declared that ICT promotes the research and project development in higher educational institutions. In case of of the statement "ICT is used to exchange the research information with other organizations" associated with variable no. 14 , there are $47 \%$ boys are agree, $17 \%$ are strongly agree, $4 \%$ are strongly disagree, $11 \%$ are disagree and $21 \%$ are undecided. It reveals that $64 \%$ boys committed that ICT is used to share and transfer the research information with other institutions and organizations. For the statement "ICT is used adequately in teaching, learning and research activities" under variable no.15, 47\% boys are agreed, 18\% are strongly agreed and 5\% are strongly disagreed, $16 \%$ are disagreed and $14 \%$ are undecided. It concludes that there is need to the involve ICT in educational and research activities in higher educational institutions. For the statement "E-journals/ E-contents are effectively using in research and development" under variable no.16, there are 32\% 
boys are agree, $14 \%$ are strongly agree, $13 \%$ are strongly disagree, $19 \%$ are disagree and $22 \%$ are undecided. It necessitates more use of E-journals / E-contents in research and development. In case of of the statement "ICT is used to access the E-contents from other libraries" associated with variable no.17, there are $43 \%$ boys are agree, $17 \%$ are strongly agree, $6 \%$ are strongly disagree, $13 \%$ are disagree and $21 \%$ are undecided. It is found that $63 \%$ boys are in favour of use of ICT to access E-contents from other libraries. In relation to variable no. 18, for statement "ICT is used to learn the lecture/lesson from other institutions experts through video conferencing", there are $43 \%$ boys are agree, $30 \%$ are strongly agree, $8 \%$ are strongly disagree, $6 \%$ are disagree and $13 \%$ are undecided. It reveals that majority of boys committed about the use of video conferencing for listening lectures from remote institutions. Under variable no. 19, for statement "Time consuming to integrate ICT into teaching, learning, research and development", there are $31 \%$ boys are agree, $16 \%$ are strongly agree, $13 \%$ are strongly disagree, $16 \%$ are disagree and $24 \%$ are undecided. It proves that fifty percent boy students are able to adapt ICT into their academics. Hence, there is wide necessity to encourage and motivate the rest of students to be aware about key benefits of ICT integration in their academia. Under variable no. 20, for statement "Lack of readiness to adopt ICT technology in Teaching and Learning", there are 39\% boys are agree, $26 \%$ are strongly agree, $3 \%$ are strongly disagree, $15 \%$ are disagree and $18 \%$ are undecided. It shows that $65 \%$ students are in favour of this statement.

For the statement "ICT tools/software not user friendly due to lack of training" under variable no.21, there are $35 \%$ boys are agree, $20 \%$ are strongly agree, $7 \%$ are strongly disagree, $16 \%$ are disagree and $22 \%$ are undecided. It proves that user-friendly ICT tools and software's should be developed. For the statement "Need to increase the latest ICT infrastructure" under variable no.22, there are $46 \%$ boys are agree, $31 \%$ are strongly agree, $4 \%$ are strongly disagree, $8 \%$ are disagree and $12 \%$ are undecided. It proves that management of institutions has to be update and enhance the ICT infrastructure in their campus for students and researchers use. For the statement "Need to increase the latest ICT infrastructure" under variable no.22, there are $46 \%$ boys are agree, $31 \%$ are strongly agree, $4 \%$ are strongly disagree, $8 \%$ are disagree and $12 \%$ are undecided. It proves that management of institutions has to be update and enhance the ICT infrastructure in their campus for students and researchers use. In case of the statement "Internet bandwidth should be increased" under variable no. 23 , there are $41 \%$ boys are agree, $42 \%$ are strongly agree, $1 \%$ are strongly disagree, $4 \%$ are disagree and $12 \%$ are undecided. It shows that there is lower Internet bandwidth provided in concerned institutions. It needs to be increase as per requirement by stakeholders. For the statement "Need to increase E-journals/ E-contents as per requirement" under variable no. 24 , there are $46 \%$ boys are agree, $31 \%$ are strongly agree, $4 \%$ are strongly disagree, $8 \%$ are disagree and $12 \%$ are undecided. It is found that $77 \%$ boys are committed about the further need to enhance E-journals in libraries. For the statement "Need to enhance ICT in Teaching and Learning" under variable no.26, there are $47 \%$ boys are agree, $34 \%$ are strongly agree, $6 \%$ are strongly disagree, $4 \%$ are disagree and $3 \%$ are undecided. It is concluded that majority of boys $(81 \%)$ are confirmed about the need to enhance ICT in education. For the statement "ICT increase the effective teaching and E-learning in classroom" under variable no.27, there are $39 \%$ boys are agree, $24 \%$ are strongly agree, $9 \%$ are strongly disagree, $11 \%$ are disagree and $16 \%$ are undecided. It is discovered that $63 \%$ boys are agreed about the statement. For the statement "Students and Teachers feel more professional, motivate, confident while using ICT resources" under variable no. 28 , there are $43 \%$ boys are agree, $30 \%$ are strongly agree, $2 \%$ are strongly disagree, $9 \%$ are disagree and $15 \%$ are undecided. It is found that majority of boy students are believed in ICT makes professional and confident to stakeholders. In case of statement "ICT provides more comprehensive material of a particular topic" under variable no.29, there are $50 \%$ boys are agree, $24 \%$ are strongly agree, $4 \%$ are strongly disagree, $8 \%$ are disagree and $13 \%$ are undecided. It is concluded that ICT provides detailed and inclusive study material about particular topic of discussion or study for stakeholders. For the statement "ICT plays an important role in Admission and Examination" under variable no. 30 , there are $44 \%$ boys are agree, $30 \%$ are strongly agree, $3 \%$ are strongly disagree, $8 \%$ are disagree and $16 \%$ are undecided. Hence, it is found that $74 \%$ boys believed that their institutions is used to ICT in academics activities such as examination and admissions of students. For the statement "Integrate of ICT increase Placement activities" under variable no.31, there are $46 \%$ boys are agree, $29 \%$ are strongly agree, $4 \%$ are strongly disagree, $9 \%$ are disagree and $13 \%$ are undecided. Hence, it is concluded that majority of boys said that ICT helps to promote job Placement of students. In case of statement "ICT reduce the cost for information exchange" under variable no. 32 , there are $48 \%$ boys are agree, $26 \%$ are strongly agree, $2 \%$ are strongly disagree, $9 \%$ are disagree and $15 \%$ are undecided. Thus, it is found that $74 \%$ boys said that ICT helps to decrease the cost of information exchange among educational institutions.

In relation to variable no. 33, for statement "ICT helps in design to new projects in higher education", there are $56 \%$ boys are agree, $31 \%$ are strongly agree, $4 \%$ are strongly disagree, $3 \%$ are disagree and $7 \%$ are undecided. It is concluded that ICT is helpful in drawing to new projects in higher education. In case of statement "Successful ICT integration will brighten the future of Higher education" under variable no. 34, there are $49 \%$ boys are agree, $35 \%$ are strongly agree, $2 \%$ are strongly disagree, $3 \%$ are disagree and $11 \%$ are undecided. It is observed according to majority of boys that ICT adaption in higher education definitely causes to lighten the educational opportunity 
Table 2. Percentage Analysis of Viewpoints of Girl Students towards ICT

\begin{tabular}{|c|c|c|c|c|c|}
\hline \multirow{3}{*}{ Dependant Variables No.s } & \multicolumn{5}{|c|}{ Girls } \\
\hline & SD & D & UD & $\mathbf{A}$ & SA \\
\hline & \multicolumn{5}{|c|}{ Percentage (\%) } \\
\hline VAR-1 & 7 & 14 & 10 & 59 & 10 \\
\hline VAR-2 & 9 & 13 & 5 & 52 & 22 \\
\hline VAR-3 & 6 & 23 & 7 & 45 & 17 \\
\hline VAR-4 & 6 & 24 & 20 & 42 & 7 \\
\hline VAR-5 & 5 & 13 & 26 & 45 & 11 \\
\hline VAR-6 & 6 & 16 & 29 & 40 & 9 \\
\hline VAR-7 & 8 & 19 & 19 & 47 & 8 \\
\hline VAR-8 & 16 & 19 & 14 & 36 & 14 \\
\hline VAR-9 & 15 & 26 & 16 & 33 & 9 \\
\hline VAR-10 & 17 & 21 & 16 & 36 & 11 \\
\hline VAR-11 & 5 & 9 & 24 & 50 & 12 \\
\hline VAR-12 & 7 & 12 & 25 & 43 & 13 \\
\hline VAR-13 & 4 & 13 & 17 & 56 & 10 \\
\hline VAR-14 & 3 & 10 & 16 & 53 & 17 \\
\hline VAR-15 & 3 & 12 & 10 & 56 & 19 \\
\hline VAR-16 & 18 & 17 & 23 & 32 & 9 \\
\hline VAR-17 & 14 & 13 & 21 & 41 & 12 \\
\hline VAR-18 & 4 & 5 & 12 & 55 & 24 \\
\hline VAR-19 & 6 & 18 & 22 & 43 & 11 \\
\hline VAR-20 & 6 & 15 & 23 & 42 & 13 \\
\hline VAR-21 & 3 & 16 & 21 & 41 & 19 \\
\hline VAR-22 & 5 & 4 & 11 & 57 & 23 \\
\hline VAR-23 & 2 & 5 & 5 & 47 & 42 \\
\hline VAR-24 & 5 & 4 & 11 & 57 & 23 \\
\hline VAR-25 & 2 & 4 & 10 & 56 & 28 \\
\hline VAR-26 & 1 & 2 & 12 & 52 & 34 \\
\hline VAR-27 & 14 & 12 & 16 & 42 & 17 \\
\hline VAR-28 & 2 & 7 & 9 & 55 & 28 \\
\hline VAR-29 & 1 & 6 & 13 & 57 & 23 \\
\hline VAR-30 & 1 & 5 & 14 & 53 & 27 \\
\hline VAR-31 & 2 & 5 & 13 & 50 & 30 \\
\hline VAR-32 & 5 & 11 & 14 & 52 & 18 \\
\hline VAR-33 & 1 & 4 & 8 & 57 & 30 \\
\hline VAR-34 & 0 & 2 & 11 & 52 & 34 \\
\hline VAR-35 & 1 & 2 & 12 & 53 & 31 \\
\hline
\end{tabular}

(Source: Author)

in arena of research and higher education. For the statement "Using the ICT available increases productivity in Higher Education" under variable no.35, there are $49 \%$ boys are agree, $32 \%$ are strongly agree, $3 \%$ are strongly disagree, $7 \%$ are disagree and $13 \%$ are undecided. Hence, it is found that ICT is supportive resource to enhance quality in education and research.

\section{PERCENTAGE ANALYSIS OF GIRL'S VIEWPOINT}

Data from Table 2 shows the Percentage Analysis of Variables for Girls towards ICT. For VAR-1, 69\% $(59+10)$ girls are in favour, 21\% $(7+14)$ not and 10\% left undecided. It shows adequate ICT infrastructure is available in institutions. For VAR-2, 74\% (52+22) girls are in favour, 22\% $(9+13)$ not and $5 \%$ left undecided. It proves almost institutions campuses are Wi-fi. In case of VAR-3, 62\% (45+17) girls are in favour, 29\% (6+23) not in favour and 7\% left undecided. It concludes more sufficient Internet bandwidth should be provided for use of stakeholders. In relation to VAR-4, 49\% (42+7) girls are in favour, 30\%(6+24) not in favour and $20 \%$ left undecided. It reveals that ICT tools/software are not easy accessible to students and educators. For VAR-5, 56\% $(45+11)$ girls are in support, 19\% (5+13) not in favour and 26\% left undecided. It shows that Institutions should make clear policy framework to integrate ICT in education. For VAR-6, 49\% (40+9) girls are in support, $22 \%(6+16)$ not in favour and 29\% left undecided. It infers that Institution's authorities should provide sufficient funds to promote ICT based research and development. For VAR-7, 53\% (47+8) girls are in favour, 27\% (8+19) not in support and 19\% remain undecided. It evident that there is need to provide sufficient ICT tools/software and hardware is available in research laboratories of concerned institutions. In relation to VAR- $8,50 \%(36+14)$ girls are in support, 35\% (16+19) not in support and 14\% remain undecided. It concludes that there is need for E-library in institutions. For VAR-9, 42\% (33+9) girls are in favour, 41\% $(15+26)$ not in favour and 16\% left 
undecided. It shows that need to enhance the availability of sufficient E-journals/ E-contents in Library. For VAR-10, 47\% (36+11) girls are in favour, 38\% (17+21) not in favour and 16\% left undecided. It presents the need of easy access of E-contents in Institutional libraries. For VAR-11, 62\% (50+12) girls are in favour, 13\% (5+9) not in favour and $24 \%$ remain undecided. It concludes that ICT is using well for Planning and Management activities of higher educational institutions. For VAR-12, 56\% (43+13) girls are in favour, 38\% $(7+12)$ not in favour and $25 \%$ remain undecided. It shows that ICT tools/software used in research and development are reliable somewhere. In case of VAR-13, 66\% (56+10) girls are in favour, 17\% $(4+13)$ not in favour and 17\% remain undecided. It infers that ICT encourages research and project development. For VAR-14, 70\% (53+17) girls are in favour, $13 \%(3+10)$ not in favour and 16\% remain undecided. It proves that ICTis used to exchange the research information with other organizations. For VAR-15, 75\% (56+19) girls are in favour, $15 \%(3+12)$ not in favour and $10 \%$ remain undecided. It shows that ICT used adequately in teaching, learning and research activities. In association with VAR-16, 41\% (32+9) girls are in favour, 35\% (18+17) not in favour and 23\% remain undecided. It concludes that there is more need to effective use of E-journals/ E-contents in research and development. For VAR-17, 53\% (41+12) girls are in favour, 27\% (14+13) not in favour and 21\% remain undecided. It shows that ICT is used to access the E-contents from other libraries. In relation to VAR-18, 79\% (55+24) girls are in favour, $9 \%(4+5)$ not in favour and $12 \%$ remain undecided. It explores that majority of girls are believed in statement "ICT is used to learn the lecture/lesson from other institutions experts through video conferencing". In relation to VAR-19, 54\% (43+11) girls are in favour, 24\% $(6+18)$ not in favour and $22 \%$ remain undecided. It explores that approximately fifty percent girls are committed to the statement "Time consuming to integrate ICT into teaching, learning, research and development".

For VAR-20, 55\% (42+13) girls are in favour, 21\% $(6+15)$ not in favour and 23\% remain undecided. It infers that stakeholders have to be producing self likekiness to adopt ICT in their educational life. For VAR-21, 60\% $(41+19)$ girls are in favour, $19 \%(3+16)$ not in favour and 21\% remain undecided. It infers that ICT tools/ software not user friendly due to lack of training. Thus, there is necessity to provide traning or workshops for learn unfriendly ICT tools. For VAR-22, 80\% (57+23) girls are in favour, 9\% (5+4) not in favour and 11\% remain undecided. It shows that there is wide need to increase the latest ICT infrastructure in concerned institutions. In case of VAR-23, 89\% (47+42) girls are in favour, 9\% $(2+5)$ not in favour and $5 \%$ remain undecided. It proves the heavy need to increase Internet bandwidth for stakeholders. In case of VAR-24, 80\% (57+23) girls are in support, $9 \%(5+4)$ not in favour and $11 \%$ remain undecided. It concludes that majority of girls wants to increase E-journals/ E-contents as per requirement. In relation to VAR-25, 84\% (56+28) girls are in support, $6 \%(2+4)$ not in favour and $10 \%$ remain undecided. It shows that most of girls have recommended the statement "Need to enhance ICT in Teaching and Learning".

In respect of VAR-26, 76\% (52+34) girls are in favour, $3 \%(1+2)$ not in favour and $12 \%$ remain undecided. It shows that most of girls recommended the statement "Need to enhance ICT in Teaching and Learning". For VAR-27, 59\% (42+17) girls are in support, 26\% (14+12) not in favour and 16\% remain undecided. It infers that ICT increase the effective teaching and E-learning in classroom. For VAR-28, 83\% (55+28) girls are in support, $9 \%(2+7)$ not in favour and 9\% remain undecided. It discovers that students and teachers feel more professional, motivate and confident while using ICT resources. In respect of VAR-29, 80\% (57+23) girls are in favour, 7\% $(1+6)$ not in favour and 13\% remain undecided. It finds that ICT provides more comprehensive material of a particular topic. In case of VAR-30, 80\% (53+27) girls are in favour, $6 \%(1+5)$ not in favour and $14 \%$ remain undecided. It explores that ICT plays an important role in Admission and Examination. For VAR-31, 80\% (50+30) girls are in favour, $7 \%(2+5)$ not in favour and $13 \%$ remain undecided. It concludes that majority of girls are shown their keen interest in the statement "Integrate of ICT increase Placement activities". In respect of VAR-32, 70\% $(52+18)$ girls are in favour, $16 \%(5+11)$ not in favour and 14\% remain undecided. It describes that ICT reduce the cost for information exchange. In case of VAR-33, 87\% (57+30) girls are in support, $5 \%(1+4)$ not in favour and $8 \%$ remain undecided. It finds that ICT helps in design to new projects in higher education. For VAR-34, 74\% $(52+34)$ girls are in favour, $2 \%$ not in favour and $11 \%$ remain undecided. It concludes that successful ICT integration will be brighten the future of Higher education. For VAR-35, 74\% (53+31) girls are in support, 3\% $(1+2)$ not in favour and $12 \%$ remain undecided. Hence, it is revealed that using the ICT available increases productivity in higher Education. 
Verma et al. / Viewpoint of Students and Faculty towards ICT

Table 3. Percentage Analysis of Viewpoints of Male and Female Faculty towards ICT

\begin{tabular}{|c|c|c|c|c|c|c|c|c|c|c|}
\hline \multirow{2}{*}{$\begin{array}{c}\text { Dependant Variables } \\
\text { No.s }\end{array}$} & \multicolumn{5}{|c|}{ Male } & \multicolumn{5}{|c|}{ Female } \\
\hline & SD & D & UD & $\mathbf{A}$ & SA & SD & D & UD & $\mathbf{A}$ & SA \\
\hline VAR-1 & $7 \%$ & $12 \%$ & $13 \%$ & $60 \%$ & $8 \%$ & $2 \%$ & $15 \%$ & $11 \%$ & $56 \%$ & $15 \%$ \\
\hline VAR-2 & $9 \%$ & $11 \%$ & $9 \%$ & $52 \%$ & $19 \%$ & $2 \%$ & $13 \%$ & $9 \%$ & $60 \%$ & $16 \%$ \\
\hline VAR-3 & $6 \%$ & $22 \%$ & $13 \%$ & $46 \%$ & $13 \%$ & $3 \%$ & $21 \%$ & $14 \%$ & $49 \%$ & $13 \%$ \\
\hline VAR-4 & $6 \%$ & $11 \%$ & $21 \%$ & $49 \%$ & $13 \%$ & $5 \%$ & $17 \%$ & $14 \%$ & $52 \%$ & $13 \%$ \\
\hline VAR-5 & $7 \%$ & $13 \%$ & $25 \%$ & $43 \%$ & $11 \%$ & $4 \%$ & $12 \%$ & $20 \%$ & $50 \%$ & $14 \%$ \\
\hline VAR-6 & $5 \%$ & $16 \%$ & $27 \%$ & $43 \%$ & $9 \%$ & $4 \%$ & $10 \%$ & $29 \%$ & $48 \%$ & $10 \%$ \\
\hline VAR-7 & $7 \%$ & $14 \%$ & $18 \%$ & $46 \%$ & $16 \%$ & $3 \%$ & $12 \%$ & $14 \%$ & $60 \%$ & $11 \%$ \\
\hline VAR-8 & $5 \%$ & $7 \%$ & $9 \%$ & $53 \%$ & $26 \%$ & $4 \%$ & $7 \%$ & $13 \%$ & $57 \%$ & $20 \%$ \\
\hline VAR-9 & $7 \%$ & $7 \%$ & $11 \%$ & $56 \%$ & $19 \%$ & $4 \%$ & $11 \%$ & $18 \%$ & $50 \%$ & $17 \%$ \\
\hline VAR-10 & $3 \%$ & $17 \%$ & $11 \%$ & $48 \%$ & $21 \%$ & $3 \%$ & $16 \%$ & $20 \%$ & $43 \%$ & $18 \%$ \\
\hline VAR-11 & $5 \%$ & $10 \%$ & $19 \%$ & $55 \%$ & $12 \%$ & $3 \%$ & $8 \%$ & $18 \%$ & $55 \%$ & $15 \%$ \\
\hline VAR-12 & $2 \%$ & $10 \%$ & $18 \%$ & $55 \%$ & $15 \%$ & $1 \%$ & $9 \%$ & $18 \%$ & $60 \%$ & $11 \%$ \\
\hline VAR-13 & $1 \%$ & $6 \%$ & $9 \%$ & $60 \%$ & $24 \%$ & $2 \%$ & $5 \%$ & $10 \%$ & $58 \%$ & $24 \%$ \\
\hline VAR-14 & $2 \%$ & $5 \%$ & $19 \%$ & $57 \%$ & $18 \%$ & $1 \%$ & $5 \%$ & $14 \%$ & $57 \%$ & $22 \%$ \\
\hline VAR-15 & $2 \%$ & $6 \%$ & $7 \%$ & $63 \%$ & $22 \%$ & $2 \%$ & $7 \%$ & $10 \%$ & $63 \%$ & $18 \%$ \\
\hline VAR-16 & $3 \%$ & $5 \%$ & $17 \%$ & $52 \%$ & $23 \%$ & $3 \%$ & $7 \%$ & $22 \%$ & $49 \%$ & $20 \%$ \\
\hline VAR-17 & $3 \%$ & $5 \%$ & $19 \%$ & $56 \%$ & $18 \%$ & $2 \%$ & $8 \%$ & $10 \%$ & $63 \%$ & $18 \%$ \\
\hline VAR-18 & $3 \%$ & $9 \%$ & $8 \%$ & $49 \%$ & $32 \%$ & $2 \%$ & $2 \%$ & $8 \%$ & $59 \%$ & $28 \%$ \\
\hline VAR-19 & $3 \%$ & $14 \%$ & $15 \%$ & $51 \%$ & $17 \%$ & $2 \%$ & $11 \%$ & $18 \%$ & $53 \%$ & $15 \%$ \\
\hline VAR-20 & $3 \%$ & $12 \%$ & $15 \%$ & $48 \%$ & $22 \%$ & $2 \%$ & $11 \%$ & $15 \%$ & $49 \%$ & $22 \%$ \\
\hline VAR-21 & $3 \%$ & $9 \%$ & $17 \%$ & $50 \%$ & $21 \%$ & $1 \%$ & $8 \%$ & $12 \%$ & $56 \%$ & $23 \%$ \\
\hline VAR-22 & $5 \%$ & $10 \%$ & $7 \%$ & $51 \%$ & $27 \%$ & $4 \%$ & $7 \%$ & $7 \%$ & $50 \%$ & $33 \%$ \\
\hline VAR-23 & $5 \%$ & $6 \%$ & $5 \%$ & $52 \%$ & $31 \%$ & $2 \%$ & $7 \%$ & $8 \%$ & $57 \%$ & $27 \%$ \\
\hline VAR-24 & $3 \%$ & $5 \%$ & $14 \%$ & $51 \%$ & $27 \%$ & $1 \%$ & $4 \%$ & $16 \%$ & $49 \%$ & $30 \%$ \\
\hline VAR-25 & $1 \%$ & $4 \%$ & $13 \%$ & $57 \%$ & $25 \%$ & $1 \%$ & $4 \%$ & $11 \%$ & $60 \%$ & $25 \%$ \\
\hline VAR-26 & $1 \%$ & $2 \%$ & $5 \%$ & $59 \%$ & $34 \%$ & $1 \%$ & $4 \%$ & $5 \%$ & $54 \%$ & $36 \%$ \\
\hline VAR-27 & $2 \%$ & $9 \%$ & $9 \%$ & $59 \%$ & $22 \%$ & $1 \%$ & $4 \%$ & $9 \%$ & $62 \%$ & $24 \%$ \\
\hline VAR-28 & $3 \%$ & $5 \%$ & $7 \%$ & $53 \%$ & $33 \%$ & $1 \%$ & $3 \%$ & $8 \%$ & $54 \%$ & $33 \%$ \\
\hline VAR-29 & $2 \%$ & $6 \%$ & $9 \%$ & $56 \%$ & $27 \%$ & $2 \%$ & $4 \%$ & $7 \%$ & $62 \%$ & $25 \%$ \\
\hline VAR-30 & $1 \%$ & $4 \%$ & $13 \%$ & $53 \%$ & $30 \%$ & $1 \%$ & $5 \%$ & $7 \%$ & $63 \%$ & $24 \%$ \\
\hline VAR-31 & $2 \%$ & $3 \%$ & $14 \%$ & $54 \%$ & $28 \%$ & $0 \%$ & $3 \%$ & $13 \%$ & $60 \%$ & $24 \%$ \\
\hline VAR-32 & $1 \%$ & $6 \%$ & $11 \%$ & $58 \%$ & $24 \%$ & $0 \%$ & $8 \%$ & $10 \%$ & $59 \%$ & $24 \%$ \\
\hline VAR-33 & $1 \%$ & $3 \%$ & $8 \%$ & $54 \%$ & $34 \%$ & $0 \%$ & $5 \%$ & $11 \%$ & $58 \%$ & $26 \%$ \\
\hline VAR-34 & $3 \%$ & $1 \%$ & $6 \%$ & $54 \%$ & $36 \%$ & $1 \%$ & $4 \%$ & $12 \%$ & $51 \%$ & $31 \%$ \\
\hline VAR-35 & $2 \%$ & $2 \%$ & $9 \%$ & $52 \%$ & $36 \%$ & $2 \%$ & $2 \%$ & $9 \%$ & $53 \%$ & $34 \%$ \\
\hline
\end{tabular}

(Source: Author)

This section explores the percentage analysis of 449 male and 455 female faculty towards 35 individual dependant variables related to information and communication technology. Table 3 shows the individual percentage of male and female faculty educators towards different variables. The data from Table 4 shows that female faculty is more agreed for 26 variables as compare to the male faculty towards ICT. The details of variables are given below:

$V A R-1(56+15=71 \%), V A R-2(60+16=76 \%), V A R-3(49+13=62 \%), V A R-4(52+13=65 \%)$,

$V A R-5(50+14=64), V A R-6(48+10=58 \%), V A R-7(60+11=71 \%), V A R-9(50+17=67 \%)$,

$V A R-11(55+15=70 \%), V A R-12(60+11=71 \%), V A R-14(57+22=79 \%), V A R-17(63+18=81 \%)$,

$V A R-18(59+28=87), V A R-20(49+22=71 \%), V A R-21(56+23=79 \%), V A R-22(50+33=83 \%)$,

$V A R-23(57+27=84 \%), V A R-24(49+30=79 \%), V A R-25(60+25=85 \%), V A R-27(62+24=86 \%)$,

$V A R-28(54+33=87 \%), V A R-29(62+25=87 \%), V A R-30(63+24=87 \%), V A R-31(60+24=84 \%)$,

$V A R-32(59+24=83 \%)$ and $V A R-33(58+26=84 \%)$.

It is also found that male faculty is more agreed for 08 variables as compare to the female faculty towards ICT. The details of these 9 variables are shown below:

$V A R-8(53+26=79 \%), V A R-10(48+21=69 \%), V A R-13(60+24=84 \%), V A R-15(63+22=85 \%)$, $V A R-16(52+23=75 \%), V A R-26(59+34=93 \%), V A R-34(54+36=90 \%)$ and $V A R-35(52+36=88 \%)$

Further, it is found that males and females faculty has equal percentage in their percentage for one variable:

$V A R-19(51+17=68 \%)$. 
The data from Table 3 evident that male faculty is more disagreed for 23 variables as compare to the female faculty towards ICT. The details of variables are given below:

$V A R-1(12+7=19 \%), V A R-2(9+11=20 \%), V A R-3(6+22=28 \%), V A R-5(7+13=20 \%), V A R-6(5+16=21 \%)$,

$V A R-7(7+14=21 \%), V A R-8(5+7=12 \%), V A R-10(3+17=20), V A R-11(5+10=15), V-12(2+10=12 \%)$,

$V A R-14(2+5=7 \%), V A R-18(3+9=12 \%), V A R-19(3+14=17 \%), V A R-20(3+12=15 \%)$,

$V A R-21(3+9=12 \%), V A R-22(5+10=15 \%), V-23(5+6=11 \%), V-24(3+5=8 \%), V-27(2+9=11 \%)$,

$V-28(3+5=8 \%), V-29(2+6=8 \%), V-31(2+3=5 \%)$.

It is also found that male faculty is less disagreed for 10 variables as compare to the female faculty towards ICT. The details of variables are given below:

$V A R-4(5+17=22 \%), V A R-9(4+11=15 \%), V A R-15(2+7=9 \%), V A R-16(3+7=10 \%), V A R-17(2+8=10 \%)$, $V A R-26(1+4=5 \%), V A R-30(1+5=6 \%), V A R-32(8 \%), V A R-33(5 \%)$ and $V A R-34(1+4=5 \%$.

It is also revealed that for three variables, male and female faculty has identical percentage of disagree towards ICT which is depicted below:

$V A R-13(1+6=7 \%), V A R-25(1+4=5 \%)$ and $V A R-35(2+2=4 \%)$.

\section{RANGE OF RESPONSE ANALYSIS}

The author applied response range analysis using various functions such as stdev $0, \operatorname{var} 0$ and average 0 in MsExcel 2007. The Response analysis explores the range of responses (RR) of students and faculty after subtraction and addition the value of standard deviation from population mean value. The following Table 4 reveals the descriptive view of responses analysis of students in relation to their gender variable. Response of participants is gathered into five point likert type scale. The likert type scale is consisted of 35- dependant variable self-report scored on a 5 point likert scale (strongly disagree $(\mathrm{SD})=1$, disagree $(\mathrm{D})=2$, undecided $(\mathrm{UD})=3$, agree $(\mathrm{A})=4$, and strongly agree $(\mathrm{SA})=5$ ). The minimum score of this scale will be 35 , if participant marks strongly disagree with all variables and maximum score will be 175 , if participants tick on strongly agree with all variables. Hence, the total scores on ranged from 35 , indicating a strongly disagree attitude toward the ICT, to a score of 175 , which would imply an strongly agree attitude toward the Internet.

Table 4 shows mean, standard deviation and range of responses ranges of boy and girl, male and female, overall male and female for five factors.

\section{Availability}

In availability factor, the mean score of boy is 3.14 and in relation to this factor, mean is deviated from standard deviation 0.05, Hence their responses lie in between the range of 3.09 to $3.19(3.14-0.05=3.09,3.14+0.05=3.19)$, which concludes range of response is equal to 'undecided to agree'(3-4). This shows that opinions of boys lie in between the range of 'undecided to agree' on scale. On another hand, mean score of availability factor for girl students is 3.30 and it is deviated from standard deviation 0.12. Hence, their responses lie in between the range of 3.18 to 3.42 , which infers range of responses is equal to 'undecided to agree'. It is concluded that girl students' responses lie in between the range of undecided to agree. The mean value of male is 3.55 and for female are 3.62, deviated from their standard deviation 0.17 and 0.11 respectively. Hence, response range for both male and female is equal to 'undecided to agree'. It implies that male and female's opinion lies in between the range of 'undecided to agree'. The overall male's mean 3.30 is deviating from 0.11 and overall female's mean 3.42 is deviating from 0.14 , which reflects the range of responses is equal to 'undecided to agree'. Hence, findings conclude that responses of both overall male and overall female students and faculty lie in between the range of undecided to agree.

\section{Usability}

In usability factor, the mean value of boy is 3.52 and for girl are 3.53, deviated from their standard deviation 0.11 and 0.55 respectively. Hence, response range for both boy and girl is equal to 'undecided to agree'. It reveals that their opinions lie in between the range of undecided to agree. The mean value of male is 3.85 and female are 3.86, deviated from their standard deviation 0.14 and 0.14 respectively. Hence, response range for both male and female is equal to 'undecided to agree'. The overall male's mean value 3.65 is deviating from 0.17 and overall female's mean score 3.65 is deviating from 0.25 , which reflects the range of responses is equal to 'undecided to agree'. Therefore, results explore that responses of both overall male and overall female faculty was remain in between the range of undecided to agree. 
Table 4. Range of Responses

\begin{tabular}{|c|c|c|c|c|c|c|c|c|c|c|c|c|c|}
\hline \multirow{2}{*}{$\begin{array}{l}\text { S. } \\
\text { No. }\end{array}$} & \multirow[b]{2}{*}{ Factors } & \multicolumn{3}{|c|}{$\begin{array}{c}\text { Boy } \\
\mathbf{N}=274\end{array}$} & \multicolumn{3}{|c|}{$\begin{array}{c}\text { Girl } \\
\mathrm{N}=286\end{array}$} & \multicolumn{3}{|c|}{$\begin{array}{c}\text { Male } \\
\mathrm{N}=175\end{array}$} & \multicolumn{3}{|c|}{$\begin{array}{l}\text { Female } \\
\mathrm{N}=169\end{array}$} \\
\hline & & $\mathbf{M}$ & SD & $\mathbf{R R}$ & $\mathbf{M}$ & SD & $\mathbf{R R}$ & $\mathbf{M}$ & SD & RR & $\mathbf{M}$ & SD & RR \\
\hline 1 & Availability (VAR 1-8) & 3.14 & 0.05 & U-A & 3.30 & 0.12 & U-A & 3.55 & 0.17 & U-A & 3.62 & 0.11 & U-A \\
\hline 2 & Usability (VAR 11-18) & 3.52 & 0.11 & U-A & 3.53 & 0.55 & U-SA & 3.85 & 0.14 & U-A & 3.86 & 0.14 & U-A \\
\hline 3 & Problem (VAR 19-21) & 3.45 & 0.10 & U-A & 3.44 & 0.00 & U-A & 3.72 & 0.05 & U-A & 3.79 & 0.13 & U-A \\
\hline 4 & Solution (VAR 22-26) & 4.07 & 0.10 & U-SA & 4.09 & 0.13 & U-SA & 4.01 & 0.14 & U-SA & 4.06 & 0.09 & U-SA \\
\hline 5 & Opportunity (VAR 9-8) & 3.91 & 0.10 & U-A & 3.93 & 0.17 & U-A & 4.07 & 0.10 & $\overline{\mathrm{U}-\mathrm{SA}}$ & 4.06 & 0.05 & $\mathrm{U}-\mathrm{SA}$ \\
\hline
\end{tabular}

\begin{tabular}{clcccccc}
\hline \multirow{2}{*}{ S. No. } & \multirow{2}{*}{ Factors } & \multicolumn{3}{c}{ Over All Males } & N=449 & \multicolumn{3}{c}{ Over All Females } \\
\cline { 2 - 7 } N=455
\end{tabular}

$(* \mathrm{RR}=$ Range of Responses, $\mathrm{SD}=$ Standard Deviation. $\mathrm{M}=$ Mean, $\mathrm{SD}=$ Strongly Disagree, $\mathrm{D}=$ Disagree, $\mathrm{UD}=$ Undecided, $\mathrm{A}=\mathrm{Agree}, \mathrm{SA}=$ Strongly Agree.) (Source: Author)

\section{Problem}

In problem factor, the mean value of boys is 3.45 and it is deviated from the standard deviation equal to 0.10 and responses lie in between the range of 3.35 to 3.55 , which infers range of responses is equal to 'undecided to agree'. But the girls haven't deviated from their mean score which is 3.44, Hence range of responses is equal to 'undecided to agree'. Hence, result reveals that responses of both boys and girls lie in between the range of undecided to agree. The mean value of male is 3.72, is deviating from the standard deviation 0.05 and responses lie in between the range of 3.67 to 3.77 , which evident range of responses is equal to 'undecided to agree'. Identical, the female mean score 3.79 is deviating from 0.13, their response range lies in between 3.66 to 3.82 . Hence range of responses is equal to 'undecided to agree'. The mean value of overall male is 3.56 and for overall female is 3.57 , is deviated from their standard deviation 0.16 and 0.12 respectively. Hence, response range for both overall male and for overall female is equal to 'undecided to agree'. It concludes that opinion of overall male and female students and faculty lies between the range of 'undecided to agree'.

\section{Solution}

In case of solution factor, the mean value of boy is 4.07 and for girl is 4.09 , is deviated from their standard deviation 0.11 and 0.13 respectively. Hence, response range for both boy and girl is equal to 'undecided to strongly agree'. It reveals that their opinions lie between the range of undecided to agree. The male's mean value 4.01 is deviating from 0.14 and female's mean score 4.06 is deviating from 0.09 , which reflects the range of responses is equal to 'undecided to strongly agree'. Hence, findings conclude that responses of both male and female faculty lie in between the range of undecided to strongly agree. Therefore, they are agreed with the given solutions. The overall male's mean value 4.04 is deviating from 0.07 and overall female's mean score 4.08 is deviating from 0.09 , which infers the range of responses is equal to 'undecided to strongly agree'. Hence, responses for both overall faculty and overall female were remaining in between the range of undecided to strongly agree.

\section{Opportunity}

In opportunity factor, the mean value of boys is 3.91 and of girls are 3.93 , is deviating 0.10 and 0.17 respectively, which infers the range of responses lie in between 'undecided to agree'. Therefore, an outcome reveals that responses of both boys and girls are lies in between the range of undecided to agree. The male's mean value 4.07 is deviating from 0.10 and female's mean score 4.06 is deviating from 0.05 , which reflects the range of responses is equal to 'undecided to strongly agree'. Recent research explores that responses of both male and female faculty was remained between the range of undecided to strongly agree. The overall male's mean value 3.97 is deviating from 0.14 and overall female's mean score 4.08 is deviating from 0.09 , which infers the range of responses is equal to 'undecided to strongly agree'. Hence, responses for both overall faculty and female were remaining in between the range of undecided to strongly agree. 


\section{LIMITATION OF STUDY}

The present study is limited to analyzing the viewpoints of faculty and students in relation to gender only. The selection of Universities are limited. This study is delimited to only two states of northern India. The utilization of descriptive statistical methods is confined to mean, standard deviation, percentage analysis and range of response analysis. The future researchers can apply more statistical methods such as T-test, Z-test, Anova and regression analysis etc.

\section{CONCLUSION}

This paper explores viewpoints of both students and faculty towards information and communication technology awareness. The response range of opinion towards availability, usability and problem factor lies in between the scale of 'undecided to agree', for all students and faculty. Therefore, all participants are found to be agreeing towards these factors. In solution factor, response range of opinion lies in between the scale of 'undecided to strongly agree', for all students and faculty. Hence, they have strongly accepted our proposed solutions to defeat existing issues regarding ICT. On one hand, for opportunity factor, response range for boy and girl lies in between the scale of 'undecided to agree'. But on the other hand, response range for male, female, overall male and female lies in between the scale of 'undecided to strongly agree'. It reviews that students and faculty want to avail every opportunity of ICT in their academic and personal life. The percentage analysis of responses of faculty and students reveals that stakeholders are almost agreed with the dependant variables. This is prime investigation is conducted by author during his tenure of research work. The findings of this research may be helpful to future researchers, ICT vendors and administration of both private and government Universities

\section{REFERENCES}

Ahamad, E. (2015). Attitudes towards Information and Communication Technology (ICT) with reference to Gender. International Journal of Applied Research, 1(7), 193-195.

Francisca, S. (2012). ICT Competency of Teacher Trainees. International Interdisciplinary Research Journal. 2(1), 47-57. Indu, H. et al. (2012). Know - How ICT among Student Teachers. International Conference on E-Governance \& Cloud Computing Services (EGov '12). Proceedings published by International Journal of Computer Applications ${ }^{\circledR}$ (IJCA), India, 11-15.

Mahajan, A. and Sharma, D. (2012). A Technical SWOT Analysis of ICT Facilities: Jammu University, Jammu, India. International Journal of Advanced Research in Computer Science and Software Engineering, 2(12), 128-139.

Nikkah, Z. and Mehra, V. (2014). Computer Competency and Attitude towards ICT among University Teachers: The Case of Punjab University, Chandigarh - India. International Journal of Teacher Educational Research, 10, 16-26. 